\title{
MEFV gene mutations and cardiac phenotype in children with familial Mediterranean fever: a cohort study
}

Samia Salah', Ranya Hegazy ${ }^{1 *}$, Rasha Ammar ${ }^{1}$, Hala Sheba $^{2}$ and Lobna AbdelRahman ${ }^{1}$

\begin{abstract}
Background: Familial Mediterranean fever (FMF) is the most common autoinflammatory disorder in the world. It is characterized by recurrent febrile inflammatory attacks of serosal and synovial membranes. MEFV gene mutations are responsible for the disease and its protein product, pyrin or marenostrin, plays an essential role in the regulation of the inflammatory reactions. Although the disease may carry a potential for cardiovascular disorders because of sustained inflammation during its course, the spectrum of cardiac involvement in children with FMF has not been well studied. We aimed at defining the frequency and spectrum of cardiac affection in children with FMF. The correlation between these affections and MEFV gene mutations was searched for to establish the relationship between cardiac phenotype and the patient's genotype in FMF.

Methods: The present work is a cohort study including 55 patients with the clinical diagnosis of FMF based on the Tel-Hashomere criteria, confirmed by genetic analysis showing homozygous or compound heterozygous mutation of MEFV genes. Fifty age- and sex-matched normal children were included as controls. The entire study group underwent detailed cardiac examination, 12-lead ECG and echocardiography. All data was statistically analysed using SPSS version-15.

Results: Patients had an average age of $8.5+/-4.2$ years; with an average disease duration of $2.1+/-2.2$ years; 28 were males. All controls showed no MEVF gene mutations. The most frequent gene mutation of the studied cases was E148Q mutation seen in 34\% of cases and the most frequent compound mutation was E148Q/N726A seen in $16.6 \%$ of cases. Echocardiographic examination revealed pericardial effusion in nine patients. Twelve had aortic regurgitation; nine had mitral regurgitation and six had pulmonary regurgitation. The most common mutation associated with pericardial effusion was E148QN726A in 5/9 of cases. Valvular involvement were significantly more common in FMF patients with gene mutations. Also cardiac involvement was more common in patients with positive consanguinity. However, these cardiac manifestations showed no correlation to age, family history of FMF, or response to therapy or laboratory data.
\end{abstract}

Conclusions: In our cohort of children with FMF, cardiac involvement appears to be common. Pericardial effusions are significantly related to presence of mutation types E48Q, P 369S, V726A. These associations may warrant genetic screening of children with FMF to detect cardiac risk.

\footnotetext{
* Correspondence: r_hegazy@hotmail.com

'Department of Pediatrics, Faculty of Medicine, Cairo University, Giza, Egypt

Full list of author information is available at the end of the article
} 


\section{Background}

Familial Mediterranean Fever (FMF) is the most common autoinflammatory. Disorder in the world [1]. It is a genetic disorder inherited as an autosomal recessive disease [2] and is characterized by recurrent febrile inflammatory attacks of serosal and synovial membranes. FMF predominantly affects the populations arising from the Mediterranean basin and seen in nearly every country [3]. Its phenotype includes recurrent attacks of peritonitis, pleuritis, pericarditis, synovitis, arthritis, and fever [4]. The Mediterranean gene (MEFV) mutations are responsible for the disease. Its protein product, pyrin or marenostrin, plays an essential role in the regulation of the inflammatory reactions. The MEFV gene contains 10 exons and most of the mutations have been found on the last exon. Up to recently, 152 mutations and polymorphisms have been reported [5].

Although the disease in adults and children may carry a potential for cardiovascular disorders because of the sustained systemic inflammation during its course [6], the spectrum of cardiac involvement in children with FMF has not been well studied [4]. Impairment of diastolic function parameters [3], pericarditis and pericardial effusion [7], atrial mechanical delay, increased $P$ wave dispersion [8], and impaired coronary microvascular function [2], have all been reported in various studies. The present work aimed at defining the frequency and spectrum of cardiac manifestations in Egyptian children with FMF. The correlation between these manifestations and MEFV gene mutations was searched for to establish the relationship between cardiac phenotype and the patient's genotype in childhood FMF.

\section{Methods}

The present work is a cohort study that included 108 children with the clinical diagnosis of Familial Mediterranean Fever. These patients were followed at the Rheumatology Clinic of the Cairo University Specialized Pediatric Hospital. IRB approval was obtained and a written informed consents were taken from all parents.

For the purpose of this study, the diagnosis of Familial Mediterranean. Fever was based on the Tel-Hashomere criteria. Patients included fulfilled 2 major or 1 major and 2 minor criteria [9].

\section{Major criteria}

1. Recurrent febrile episodes accompanied by peritonitis, synovitis or pleuritis.

2. Amyloidosis of AA-type without predisposing disease.

3. Favorable response to continuous colchicine treatment.

\section{Minor criteria}

1. Recurrent febrile episodes.

2. Erysipelas-like erythema.

3. FMF in a first-degree relative.

FMF patients were included if under 16 years regardless of sex, duration of FMF, age of onset, duration of FMF attacks, frequency of attacks, family history of FMF, or clinical presentation. Fifty age and sex matched normal children were included as controls.

\section{Data collected}

\section{Detailed history}

History of FMF including:

a. Patient's age at inclusion and age at onset of FMF.

b. Duration of FMF, duration \& frequency of FMF attacks.

c. History of the presenting features (e.g., typical attacks of fever, abdominal pain, chest pain, joint disease, skin affection, muscle pain, scrotal pain, and history of vomiting).

d. History of renal involvement (amyloidosis, proteinuria or haematuria).

e. History of a laparotomy.

f. History of colchicine medication and response to therapy.

g. Family history including: parental consanguinity, history of FMF and history of siblings with FMF.

\section{Complete clinical examination}

The exam included vital signs and anthropometric measurements for height, and weight. Body mass index was calculated as weight $(\mathrm{Kg}) /$ height $\left(\mathrm{m}^{2}\right)$. A detailed physical examination was performed with a particular emphasis on the cardiac examination.

\section{Laboratory investigations}

a. $6 \mathrm{ml}$ of venous blood was collected under aseptic conditions for CBC, ESR and CRP.

b. Mutation analysis: $3 \mathrm{ml}$ of blood was collected for mutation analysis.

Genomic DNA was extracted from the whole blood according to the standard procedures using QlAamp Spin Columns by QlA amp DNA Blood Kits [Cat.No.51104] [10]. The MEFV gene contains 10 exons and most of the mutations have been found on the last exon. As of this publication submission, 152 mutations and polymorphisms have been reported. Five mutations account for $70 \%$ of the deleterious alleles: M694V, V726A, M680I, M694I, E148Q. Four other mutations are less frequent: 
A744S, I692del, R761H, F479L. Other mutations detected were P369S, K695R. These eleven mutations were searched for. Specimens and DNA extraction: Genomic DNA was extracted from acid citrate-dextrose-anticoagulated whole-blood specimens using the Genovision GenoM -96 platform according to the manufacturer's instructions.

Detection of FMF mutations: A laboratory-developed test using the ABIPRISM SNaPshot Multiplex kit, regions of exons 2, 3, 5, and 10 of the MEFV gene were amplified by multiplex polymerase chain reaction (PCR) and the amplicons were used as templates in single base-pair extension (SNaPshot) reaction.

Mutations in the 158 samples were assessed by amplifying genomic DNA with use of primers [11]. M694V, V726A, M680I, M694I, E148Q, A744S, I692del, R761H, F479L, P369S, K695R mutations were analyzed by amplification refractory mutation system (ARMS).

\section{Mutation detection by ARMS}

The ARMS assay comprises two complementary reactions each conducted with the same substrate DNA. One reaction includes an ARMS primer specific for the normal DNA sequence and cannot amplify mutant DNA at a given locus. The second reaction includes a mutantspecific primer and cannot amplify normal DNA. The same common primer is used in both reactions.

The lack of polymerase chain reaction (PCR) products according to the use of a specific mutation primer set in patients suspected of carrying the mutation of FMF suggests that the patient in question is not carrying the mutation being probed [12]. However, an appropriate internal PCR control should be run to show that the DNA is amplifiable. Therefore, the complementary reaction with the normal primer set serves as an internal control for PCR amplification and allows discrimination of homozygotes from heterozygotes [12].

Mutations were assessed by amplifying the genomic DNA template with three sets of normal and mutantspecific ARMS primers designed to selectively amplify the normal or altered sequence of each of the three $M E F V$ mutations. Each set of primers consisted of three oligonuleotides. Each DNA sample was tested for the twelve mutations. The PCR amplification was performed in a final volume of $25 \mathrm{uL}$ containing $100 \mathrm{ng}$ of purified genomic DNA, 0.04 U of Ampli Tag Gold (Perkin Elmer, Branchburg, New Jersey) and its PCR buffer (contains $15 \mathrm{mmol}$ of MgCL2 per U), $0.2 \mathrm{mmol}$ of deoxynucleoside 5'-triphosphate mix per L (Gibco BRL, Gautherburg, Maryland), and $1 \mathrm{mmol}$ of each primer.

Amplification conditions were kept the same for all the ARMS tests, and the procedure was carried out as follows: The reaction was heated to $94^{\circ} \mathrm{C}$ for 9 minutes for denaturation, followed by 35 cycles with denaturation at $94^{\circ} \mathrm{C}$ for 10 seconds, and extension at $72^{\circ} \mathrm{C}$ for 30 seconds. Final extension was done for 10 minutes at $72^{\circ} \mathrm{C}$.

The amplified products were separated by electrophoresis on $2 \%$ agarose gel. Ethidium bromide staining of the agarose gel was used to detect the amplified fragments [13-15]. Further mutation screening was performed through bidirectional automated DNA sequencing using the MEFV sequence analysis kit (Canterbury Health Laboratories) to identify the compound heterozygote under complete aseptic conditions after withdrawing $0.5 \mathrm{ml}$ of EDTA blood. The DNA sequence variations were identified per reference sequence.

\section{Collection of urine samples}

Urine samples were collected for urine analysis to detect the presence of abnormalities especially proteinuria or hematuria.

\section{Electrocardiogram (ECG)}

All routine measurements were taken and any ECG abnormalities were noted.

\section{Echocardiography}

Echocardiographic examination was performed at the echocardiography lab CUSPH of Medicine Cairo University. Transthoracic two dimensional (2D) guided, (M. mode), color Doppler echocardiogram, and continuous wave Doppler CW were performedwith a Hewlett-Packard 5500 ultrasonic machine phased array sector scanner with the 4 and 8 probes according to age. Linear measurements of LV cavity were obtained. Left ventricle end diastolic diameter (LVEDD), left ventricle end systolic diameter (LVESD), interventricular septum (IVS) and posterior wall (PW) and calculation of fractional shortening (FS\%) as an indicator of LV systolic function were done according to the recommendations of the American Society of Echocardiography. FS value $<28 \%$ were considered lower than

Table 1 Demographic data of the clinically diagnosed FMF

\begin{tabular}{llll}
\hline & Cases $(\mathbf{n}=\mathbf{1 0 8})$ & Controls $(\mathbf{n}=\mathbf{5 0})$ & P value \\
\hline Mean age & $8.5 \pm 4.2$ & $8.6 \pm 3.9$ & 0.78 \\
Range & $2-17$ & $3-15$ & \\
Sex & & & \\
Male & $55(50.9 \%)$ & $23(46 \%)$ & 0.47 \\
BMI & $21.2 \pm 5.1$ & $24.5 \pm 6.7$ & 0.69 \\
+ve FH of FMF & $21(19.4 \%)$ & 0 & 0.02 \\
+ve consanguinity & $43 .(39.8 \%)$ & $20(10 \%)$ & 0.21 \\
Age at onset & $6.3 \pm 11.3$ ys & - & \\
Time to diagnosis & $1.2 \pm 0.4$ ys & & \\
Duration & $2.1 \pm 2.2$ ys & & \\
\hline
\end{tabular}

BMI: body mass index FH: Family history. 
Table 2 Clinical Manifestations of the study group

\begin{tabular}{lll}
\hline Clinical manifestations & No & Percent \\
\hline Abdominal pain & 106 & $98.1 \%$ \\
Fever & 102 & $94.4 \%$ \\
Arthralgia & 84 & $77.8 \%$ \\
Myalgia & 81 & $55.0 \%$ \\
Arthritis & 54 & $50.0 \%$ \\
GITS & 53 & $49.1 \%$ \\
Chest pain & 47 & $43.5 \%$ \\
Skin rash & 41 & $38.0 \%$ \\
Neurological symptoms & 11 & $10.2 \%$ \\
Appendicectomy & 3 & $2.7 \%$ \\
Scrotal involvement & 2 & $3.6 \%$ \\
Renal symptoms & 0 & $0.0 \%$ \\
\hline
\end{tabular}

GITS: gastrointestinal symptoms.

normal with impaired LV systolic function [16]. Left ventricular mass $(L V M)$ was estimated by using the anatomically validated formula of Devereux et al. [17]. Myocardial performance index (MPI), early diastolic peak flow velocity (A) and E/A ratio were calculated [18].

The echocardiographers were blinded as to whether the examined study participant was a case or a control. Data were statistically described in terms of range, mean \pm standard deviation $( \pm \mathrm{SD})$, frequencies (number of cases) and percentages when appropriate. Comparison of quantitative variables between the study groups was done using Student $t$ test for independent samples in comparing 2 groups when normally distributed and Mann Whitney $U$ test for independent samples when not normally distributed. For comparing categorical data, Chi square (c2) test was performed. Exact test was used instead when the expected frequency was less than 5 . A probability value ( $\mathrm{p}$ value) less than 0.05 was considered statistically significant. All statistical calculations were done using computer programs Microsoft Excel 2007 (Microsoft Corporation, NY, USA) and SPSS (Statistical Package for the Social Science; SPSS Inc., Chicago, IL, USA) version 15 for Microsoft Windows.

Table 3 Laboratory Investigations of the Study Group

\begin{tabular}{lllll}
\hline & Mean & SD & Median & Range \\
\hline ESR $\mathbf{m m H g}$ & 30.9 & 31 & 19 & $5-150$ \\
Creatinine mg/dl & 0.53 & 0.13 & 0.5 & $0.1-1$ \\
HB g/dl & 11.1 & 1.5 & 11.3 & $6.2-14$ \\
TLC & 8.1 & 4.4 & 7.2 & $3-31$ \\
Neut. \% & 51.1 & 16.7 & 50 & $17-86$ \\
\hline
\end{tabular}

ESR: erythrocyte sedimentation rate. TLC: total leucocytic count.
Table 4 The different mutation types of MEFV gene among the cases

\begin{tabular}{llll}
\hline Mutation type & E148Q & Count & Cases \\
& & \% within group & 35 \\
& M680I & Count & $34.0 \%$ \\
& & \% within group & 19 \\
& M694I & Count & $18.4 \%$ \\
& P3695 & Count within group & $14.6 \%$ \\
& & \% within group & $5.8 \%$ \\
& V726A & Count & 29 \\
& & \% within group & $28.2 \%$ \\
Total & Count & 103 \\
& & \% within group & $95.4 \%$ \\
\hline
\end{tabular}

\section{Results}

The demographic data of the study group is shown in Table 1. Abdominal pain was the most common clinical presentation of FMF in our group $(n=106,98 \%)$ followed by fever in $102(94.4 \%)$ patient. Other manifestations are shown in Table 2. The laboratory investigations of the FMF cases showed that $53.7 \%(\mathrm{n}=58)$ had positive urinary casts, $31.5 \%(n=34)$ had oxalates and $20.4 \%(n=22)$ had proteins in their urinanalysis. Twelve percent $(n=13)$ had high CRP levels. Erythrocyte sedimentation rate, creatinine levels and CBC are shown in Table 3. All controls showed no MEVF gene mutation. Five (4.6\%) of the FMF cases showed normal gene analysis while 103 (95.4\%) showed gene mutations. Two female FMF

Table 5 Compound mutations among the FMF cases

\begin{tabular}{|c|c|c|c|}
\hline & & & Cases \\
\hline \multirow[t]{14}{*}{ Mutation type } & E148Q/M680I & Count & 10 \\
\hline & & $\%$ within group & $34.0 \%$ \\
\hline & E148Q multiple allele & Count & 7 \\
\hline & & $\%$ within group & $6.4 \%$ \\
\hline & $\mathrm{E} 148 \mathrm{Q} / \mathrm{M} 6941$ & Count & 6 \\
\hline & & $\%$ within group & $18.4 \%$ \\
\hline & E148Q/V726A & Count & 18 \\
\hline & & $\%$ within group & $13.6 \%$ \\
\hline & V726A multiple allele & Count & 4 \\
\hline & & $\%$ within group & $3.7 \%$ \\
\hline & M680I/P369S & Count & 3 \\
\hline & & $\%$ within group & $5.8 \%$ \\
\hline & M6941/V726A & Count & 5 \\
\hline & & $\%$ within group & $28.2 \%$ \\
\hline \multirow[t]{2}{*}{ Total } & & Count & 53 \\
\hline & & $\%$ within group & $49 \%$ \\
\hline
\end{tabular}


Table 6 Cardiac manifestations seen in 39/55 cases

\begin{tabular}{lll}
\hline & & Group cases $(\mathbf{n}=\mathbf{5 5})$ \\
\hline Dyspnea & No & 17 \\
Palpitation & $\%$ & $31 \%$ \\
& no & 23 \\
LL oedema & $\%$ & $59 \%$ \\
Syncope & no & 4 \\
& $\%$ & $7.2 \%$ \\
& no & 5 \\
\hline
\end{tabular}

cases showed homozygosity while the rest were heterozygous. Fifth-three (49\%) showed compound heterozygous mutations. The different gene mutations are shown in Tables 4 and 5 .

The most frequent gene mutation of the studied cases was E148Q mutation, seen in 34\% of cases and the most frequent compound mutation was E148Q/V726A (16.6\%). Importantly, all patients with simple heterozygous mutations were excluded from the present work.

Seventy-four percent $(n=39)$ of the FMF patients showed a good response to therapy. This "good response" was defined by less than 2 attacks/year while $26 \%(n=14)$ showed fair response, defined by 4-5 attacks/year. None of our FMF patients were resistant to treatment.

\section{Cardiac evaluation of FMF patients}

Thirty-nine FMF cases (74\%) had cardiac complaints; the most common of which was palpitations in 59\% (Table 6). Many patients showed more than one complaint. All patients had normal blood pressure. Echocardiographic testing revealed pericardial effusions in 9 patients. Seven had mild and 2 had moderate effusions. None had cardiac tamponade. Twelve had aortic regurgitation: 8 had grade I and 3 had grade II. Nine had mitral regurgitation: 5 had grade I, 3 had grade II, and 1 had grade III. Six had pulmonary regurgitation; all 6 were grade I. All patients had sinus rhythm with normal axis. No significant differences were noted on 12 lead ECG between both the two groups.

\section{Relation between cardiac involvement and gene mutations}

The most common mutation associated with pericardial effusion was E148Q/V726A (5/9 cases). The next most common association was the E148Q multiple allele mutation (3/9 cases). The M680I/ P369S mutation was present in $1 / 9$ of cases. Valvular involvement of the heart was significantly more common in FMF patients with gene mutations and only one patient with no FMF gene mutation had mild mitral regurgitation. Cardiac involvement was significantly more common in patients with compound heterozygous mutations $(n=27)$ as compared to those with simple mutations $(\mathrm{n}=12, \mathrm{p}=0.003)$. The distribution of valvular disease among the different gene mutations are shown in Table 7. E148Q mutation was the most commonly identified mutation among FMF patients with cardiac involvement. Cardiac involvements were more common in patients with positive consanguinity $(p=0.035)$. However, cardiac disease in these patients showed no correlation to age, family history of FMF, response to therapy, or laboratory data.

\section{Discussion}

Defining children with FMF has proved more challenging than previously thought. FMF has traditionally been considered an autosomal recessive disease. However clinical phenotypes among patients who are heterozygous for FMF has been repeatedly reported and the genetics of FMF has been found more complex than previously appreciated, suggesting partial penetrance and variable expression [19].

Heterozygous FMF patients tend to have mild disease. Patients with other inflammatory conditions as Behcet's disease and tuberculosis [20] have been found to test positive for MEFV gene mutation. The vast majority of these Behcet's and TB patients have single mutations [21]. For patient selection we have excluded heterozygous FMF patients with single gene mutations and included only homozygous FMF patients and those with compound heterozygous mutations.

The present work reports an incidence of pericarditis of $16.4 \%$ and valvular involvement of $49 \%$ in these

Table 7 Frequency of valvular lesions among the different Gene mutation type

\begin{tabular}{|c|c|c|c|c|c|c|c|c|}
\hline & & \multicolumn{7}{|c|}{ Mutation type } \\
\hline & & E148Q/M680I & E148Q & E148Q/M6941 & E148Q/V726A & V726A & M680I/P369S & M6941/V726A \\
\hline \multirow[t]{2}{*}{ Pulmonary $(n=6)$} & no & 1 & 1 & 2 & 0 & 2 & 0 & 0 \\
\hline & $\%$ & $16.6 \%$ & $16.6 \%$ & $33.3 \%$ & $0.0 \%$ & $33.3 \%$ & $0 \%$ & $0 \%$ \\
\hline \multirow[t]{2}{*}{ Mitral $(n=9)$} & no & 2 & 3 & 0 & 1 & 3 & 0 & 0 \\
\hline & $\%$ & $22.2 \%$ & $33.3 \%$ & $0.0 \%$ & $11.1 \%$ & $33.3 \%$ & $0 \%$ & $0 \%$ \\
\hline \multirow[t]{2}{*}{ Aortic $(n=12)$} & no & 4 & 2 & 4 & 1 & 0 & 0 & 1 \\
\hline & $\%$ & $33.3 \%$ & $16.6 \%$ & $33.3 \%$ & $8.3 \%$ & $0 \%$ & $0 \%$ & $8.3 \%$ \\
\hline
\end{tabular}


children with these homozygous and compound heterozygous FMF mutations. The valvular disease detected consisted of aortic (21.8\%), mitral (16\%), and pulmonary regurgitation (11\%) involvement.

In a study by Maisch et al. [22], $5 \%$ of patients with FMF (adults) were found to present to the emergency department for non-acute myocardial infarction-type chest pain mainly accounted for by pericarditis. Recurrent pericarditis may occur in $15-30 \%$ of FMF patients. Examination of the pericardial fluid typically reveals activation of proinflammatory cytokines such as IL-6, IL-8, and interferon gamma [23]. Reports on the frequency of pericarditis in FMF are quite variable. In a retrospective study by Kees et al. [24] that included 4000 FMF patients during a 20 year period, the prevalence of pericarditis was reported to be $0.7 \%$. The Turkish FMF study group reported the incidence of pericarditis to be $1.4 \%$ in a cohort study [25]. Dabestani etal. [26], though, reported a much higher prevalence $(27 \%)$ of pericarditis in patients with FMF. The often asymptomatic course of pericarditis in most cases of FMF and the various diagnostic methods of detecting pericarditis are most likely responsible for these variations [27].

Certain mutations in the MEVF gene result in uncontrolled neutrophil activation and inflammation in several tissues. However, the present work suggests that the mutations in the E 148Q and V726A are most commonly associated with pericarditis in contrast to other mutations. This finding suggests that cardiac screening in patients with FMF gene mutation prone to pericarditis may be useful. It is important to emphasize for the clinician that FMF should be also considered in children presenting with non-infectious pericarditis. Cardiac functions were well preserved in our patients with FMF.

Previous studies have shown that left ventricular diastolic function indices are commonly impaired in FMF patients [28]. Systolic dysfunction and cardiac failure commonly follow these alterations in LV diastolic functions [29]. None of these changes were observed in our patients. This may be due to the younger age of our study population and hence the shorter duration of disease and less time for chronic changes, as it appears that the main pathophysiologic mechanism for these impairments may be the chronic inflammation over time. This chronic inflammation through a cumulative effect may accelerate the development of atherogenesis and thrombosis [28]. Subclinical amyloidosis might be another factor in the pathogenesis of diastolic dysfunction in this disease, again a pathology progressive with time [30].

On the other hand, cardiac function has been investigated in children with FMF by using conventional \& tissue Doppler imaging [3]. Systolic function was found to be normal, while diastolic dysfunction was reported. This was not observed in this study. Valvular involvement was noted in 27 (49\%) of our patients. No correlation was found between valvular involvement \& the type of genetic mutations. However, none of the children with FMF showed valvular disease in the absence of genetic mutations. Further studies including a larger number of children will be needed to further evaluate these associations.

\section{Conclusions}

Cardiac involvement is common in children with FMF. Pericardial effusions are significantly related to the presence of mutation types E 148Q, P 369S, V726A. These associations suggest the possibility that genetic screening of FMF patients to detect risk for significant FMF heart involvement may be prudent.

\section{Abbreviations}

FMF: Familial Mediterranean fever; MEFV: Mediterranean fever gene; PCR: Polymerase chain reaction.

\section{Competing interest}

The authors declare that they have no competing interest.

\section{Authors' contributions}

SS carried out study design, analysis of data and revision of manuscript. $\mathrm{RH}$ participated in acquisition and analysis of data, carried out drafting and submitting the manuscript. RA participated in study design, acquisition and analysis of data. HS participated in acquisition and analysis of data. LM participated in study design, acquisition and analysis of data. All authors read and approved the final manuscript.

\section{Author details}

${ }^{1}$ Department of Pediatrics, Faculty of Medicine, Cairo University, Giza, Egypt. 2Department of Clinical Pathology, Faculty of Medicine, Cairo University, Giza, Egypt.

Received: 5 January 2013 Accepted: 6 January 2014

Published: 16 January 2014

\section{References}

1. Ozen S, Aktay N, Lainka E, Duzova A, Bakkaloglu A, Kallinich T: Disease severity in children and adolescents with familial Mediterranean fever: a comparative study to explore environmental effects on a monogenic disease. Ann Rheum Dis 2009, 68(2):246-248. doi: 10.1136/ard.2008.092031. Epub 2008 Sep 18.

2. Caliskan M, Gullu H, Yilmaz S, Erdogan D, Unler GK, Ciftci O, Topcu S, Kayhan Z, Yucel E, Muderrisoglu H: Impaired coronary microvascular function in familial Mediterranean fever. Atherosclerosis 2007, 195(2):e161-167.

3. Baysal T, Peru H, Oran B, Sahin TK, Koksal Y, Karaaslan S: Left ventricular diastolic function evaluated with tissue Doppler imaging in children with familial Mediterranean fever. Clin Rheumatol 2009, 28(1):23-28. doi: 10.1007/s10067-008-0976-z. Epub 2008 Aug 8.

4. Tavil Y, Ureten K, Oztürk MA, Sen N, Kaya MG, Cemri M, Cengel A: The detailed assessment of left and right ventricular functions by tissue Doppler imaging in patients with familial Mediterranean fever. Clin Rheumatol 2008, 27(2):189-194.

5. Gunel-Ozcan A, Sayin DB, Misirlioğlu ED, Güliter S, Yakaryilmaz F, Ensari C: The spectrum of FMF mutations and genotypes in the referrals to molecular genetic laboratory at Kirikkale University in Turkey. Mol Biol Rep 2009, 36(4):757-760. 13. doi: 10.1007/s11033-008-9240-5. Epub 2008 Apr 4.

6. Köklü S, Oztürk MA, Balci M, Yüksel O, Ertenli I, Kiraz S: Interferon-gamma levels in familial Mediterranean fever. Joint Bone Spine 2005, 72(1):38-40.

7. Terekeci HM, Ulusoy ER, Kucukarslan NM, Nalbant S, Oktenli C: Familial Mediterranean fever attacks do not alter functional and morphologic 
tissue Doppler echocardiographic parameters. Rheumatol Int 2008, 28(12):1239-1243. doi:10.1007/s00296-008-0648-y. Epub 2008 Jul 23.

8. Acar G, Akcay A, Sayarlioglu M, Sokmen A, Sokmen G, Koroglu S, Gunduz M, Ispiroglu M, Tuncer C: Assessment of atrial conduction time in patients with familial Mediterranean fever. Pacing Clin Electrophysiol 2009, 32(3):308-313. doi: 10.1111/j.1540-8159.2008.02237.x.

9. Livneh A, Langevitz P, Zemer D, Zaks N, Kees S, Lidar T, Migdal A, Padeh S, Pras M: Criteria for the diagnosis of familial Mediterranean fever. Arthritis Rheum 1997, 40(10):1879-1885.

10. Solak M, Yildiz H, Koken R, Erdogan M, Eser B, Sen T, Evirgen N, Erdem S, Arikan E: Analysis of familial Mediterranean fever gene mutations in 202 patients with familial Mediterranean fever. Genet Test 2008, 12(3):341-344. doi: 10.1089/gte.2008.0009.

11. Eisenberg S, Aksentijevich I, Deng Z, Kastner D, Matzner Y: Diagnosis of Familial Mediterranean Fever by a Molecular Genetics Method. Ann Intern Med 1998, 129(7):539-542.

12. Mikula M, Buller A, Sun W, Strom CM: Prevalence of known mutations in the familial Mediterranean fever gene (MEFV) in various carrier screening populations. Genet Med 2008, 10(5):349-352. doi: 10.1097/GIM.0b013e3181723cc8.

13. Atagunduz MP, Tuglular S, Kantarci G, Akoglu E, Direskeneli H: Association of FMF-related (MEFV) point mutations with secondary and FMF amyloidosis. Nephron Clin Pract 2004, 96(4):c131-c135.

14. Kinikli G, Bektaş M, Misirlioğlu M, Ateş A, Turgay M, Tuncer S, Kinikli S, Tokgöz G: Relationship between HLA-DR, HLA-DQ alleles and MEFV gene mutations in Familial Mediterranean fever (FMF) patients. Turk Gastroenterol 2005, 16(3):143-146.

15. Mattit H, Joma M, Al-Cheikh S, El-Khateeb M, Medlej-Hashim M, Salem N Delague $V$, Mégarbané A: Familial Mediterranean fever in the Syrian population: gene mutation frequencies, carrier rates and phenotype-genotype correlation. Eur J Med Genet 2006, 49(6):481-486.

16. Sahn DJ, DeMaria A, Kisslo J, Weyman A: Recommendations regarding quantitation in M-mode echocardiography: results of a survey of echocardiographic measurements. Circulation 1978, 58:1072-1083.

17. Devereux RB, Reichek N: Echocardiographic determination of left ventricular mass in man. Anatomic validation of the method. Circulation 1977, 55:613-618.

18. Gaibazzi N, Petrucci N, Ziacchi V: Left ventricle myocardial performance index derived either by conventional method or mitral annulus tissue-Doppler: a comparison study in healthy subjects and subjects with heart failure. J Am Soc Echocardiogr 2005, 18(12):1270-1276.

19. Marek-Yagel D, Berkun Y, Padeh S, Abu A, Reznik-Wolf H, Livneh A, Pras M: Pras. Clinical disease among patients heterozygous for familial Mediterranean fever. Arthritis Rheum 2009, 60:1862-1866.

20. Booth DR, Gillmore JD, Lachmann HJ, Booth SE, Bybee A, Soyturk M: The genetic basis of autosomal dominant familial Mediterranean fever. QJM 2000, 93:217-221.

21. Holmes AH, Booth DR, Hawkins PN: Familial Mediterranean fever gene. N Engl J Med 1998, 338:992-993.

22. Maisch: Recurrent pericarditis: mysterious or not so mysterious? Eur Heart J 2005, 26(7):631-633.

23. Pankuweit S, Wädlich A, Meyer E, Portig I, Hufnagel G, Maisch B: Cytokine activation in pericardial fluids in different forms of pericarditis. Herz 2000, 25(8):748-754

24. Kees S, Langevitz P, Zemer D, Padeh S, Pras M, Livneh A: Attacks of pericarditis as a manifestation of familial Mediterranean fever (FMF). QJM 1997, 90(10):643-647.

25. Tunca M, Ozdogan $\mathrm{H}$ : Molecular and genetic characteristics of hereditary autoinflammatory diseases. Curr Drug Targets Inflamm Allergy 2005, 4(1):77-80.

26. Dabestani A, Noble LM, Child JS, Krivokapich J, Schwabe AD: Pericardial disease in familial Mediterranean fever: an echocardiographic study. Chest 1982, 81(5):592-595.

27. Okutur K, Seber S, Oztekin E, Bes C, Borlu F: Recurrent pericarditis as the initial manifestation of familial Mediterranean fever. Med Sci Monit 2008, 14(12):CS139-CS141.

28. Ozdemir O, Agras Pl, Aydin Y, Hizli S, Fidan C: Assessment of cardiac functions using Tissue Doppler imaging in children with familial Mediterenean fever. Cardiol Young 2012, 22(2):188-193.
29. Ozkan M, Emel O, Ozdemir M, Yurdakul S, Koçak H, Ozdoğan H, Hamuryudan V, Dirican A, Yazici H: M-mode, 2-D and Doppler echocardiographic study in 65 Patients with Behçet's syndrome. Eur Heart J 1992, 13(5):638-641.

30. Obici L, Merlini G: Amyloidosis in autoinflammatory syndromes. Autoimmun Rev 2012, 12(1):14-17. doi: 10.1016/j.autrev.2012.07.016. Epub 2012 Aug 2.

doi:10.1186/1546-0096-12-5

Cite this article as: Salah et al.: MEFV gene mutations and cardiac phenotype in children with familial Mediterranean fever: a cohort study. Pediatric Rheumatology 2014 12:5.

\section{Submit your next manuscript to BioMed Central and take full advantage of:}

- Convenient online submission

- Thorough peer review

- No space constraints or color figure charges

- Immediate publication on acceptance

- Inclusion in PubMed, CAS, Scopus and Google Scholar

- Research which is freely available for redistribution 